\title{
PRESIDENCIALISMO Y MONARQUÍA: OCASO Y SIMILITUDES
}

\author{
Asael Mercado Maldonado \\ Universidad Iberoamericana, México \\ Jorge Olvera García \\ Universidad Autónoma del Estado de México \\ Omar Olvera Herreros \\ Universidad Autónoma del Estado de México
}

\begin{abstract}
Resumen.- A lo largo de la historia moderna de la democracia, y desde que Charles de Secondat escribe su obra L'espirit des lois en 1748 en donde plasma la teoría de la separación de poderes, grandes autores se han empeñado en consagrar esta teoría en una forma de gobierno ideal, misma que para la teoría liberal se consolidó en la forma de gobierno presidencial modelada en la constitución federal de los Estados Unidos de Norteamérica de 1787. Montesquieu escribe su obra, momentos en los cuales el régimen monárquico se encontraba en evidente desventaja frente al crecimiento del Parlamento inglés y la consolidación de la forma de gobierno parlamentaria, por lo cual se requería una nueva forma de gobierno que mantuviera, por lo menos medianamente, los privilegios de las élites favorecidas por la corona, es así como se concibe el régimen presidencial.
\end{abstract}

Palabras clave.- Democracia, monarquía, presidencialismo, separación de poderes, responsabilidad política.

\begin{abstract}
Trough the modern history of democracy, and since Charles de Secondat wrote his work L'espirit des lois in 1748 in which he express the powers separation theory, remarkable authors have been working on consecrating this theory on an ideal government form, which the liberal theory saw consolidated on the presidential form shaped on the United States of America federal constitution of 1787 . Montesquieu wrote his work, moments on which monarchic regime was on evident risk because of the growth of English parliament and the consolidation of parliamentarism way of government, motive enough to shape a new government form which maintains, at least moderately, the privileges of the crowned favored elites, this is how presidentialism it's conceived.
\end{abstract}

Keywords.- Democracy, monarchy, presidentialism, powers separation, political responsibility.

\section{Introducción}

El propósito central de este artículo es demostrar que el presidencialismo fue durante muchos años un régimen diseñado para disimular el poder omnímodo similar a una monarquía. Si bien es cierto no es igual a una monarquía presenta rasgos y tendencias en el ejercicio del poder que incluso las monarquías tradicionales pudieran envidiar. Entendemos por presidencialismo la forma de 
gobierno presidencial cuya figura y autoridad máxima es el presidente, heredero del poder del llamado tlatoani en Mesoamérica.

Analizar comparativamente el presidencialismo con una monarquía pareciera aventurado e invita a la alarma en primer momento, y a la reflexión en un segundo, para cualquier ciudadano que habite en un Estado cuyo régimen sea el presidencialista y posea una idea por lo menos vaga de lo que una monarquía representa; para este individuo imaginario la respuesta al comparativo sería a priori negativa, toda vez que este ciudadano ha colaborado a la composición de los órganos constituidos del Estado mediante el voto libre, universal y secreto, sus gobernantes se han elegido de forma periódica, y además no es víctima de ningún tipo de violación a sus libertades de expresión o de asociación.

El presidencialismo y la monarquía son regímenes políticos, o bien formas de gobierno, y no tipos de Estado, confusión que prevalece a menudo en quienes no han tenido la cautela de ahondar en el estudio de la ciencia constitucional. Un tipo de Estado es precisamente el conjunto de elementos fundamentales y constitucionales que delimitan la manera en la cual se distribuye la soberanía, es decir la primigenia fuente del poder político, así como la finalidad del ejercicio de tal poder:

"El tipo de Estado se refiere a los fundamentos ideológicos y a la teleología del poder, de tal manera que los unos y la otra determinan el "qué" y el "para qué" de la organización del poder político" (Covián, 2008:13)

Es así como podemos comprender que un ejemplo de tipo de Estado podría ser el democrático, mismo que determina al pueblo como génesis y objeto del poder político, es decir el "qué" es el pueblo, y el "para qué" es el beneficio del mismo. Otro tipo de Estado sería el autocrático, en donde el summa potestas es detentado exclusivamente por un individuo, de forma que es él mismo el "qué" y el "para qué" del poder político.

Dentro del estudio de un tipo de Estado es necesario abarcar las dos variables antes mencionadas, origen y teleología del poder político, pues si nos limitamos exclusivamente a una caeríamos en una irresponsabilidad académica considerable, de tal manera que podríamos afirmar que una forma monárquica de gobierno podría corresponder a un tipo de Estado democrático cuando la primera incluyera en su teleología el respeto a derechos individuales y sociales de los gobernados; o bien que el presidencialismo corresponde al tipo de Estado democrático en tanto sus gobernantes son electos por la vía del sufragio, aún cuando la finalidad del poder sea el beneficio de algunos grupos minoritarios; estos dos supuestos serían válidos si se estudiase sólo una variable distintiva del tipo de Estado, en el primer caso se analiza la teleología del poder en exclusiva, ignorando por completo el origen del mismo, en consecuencia una monarquía podría ser democrática si sus fines así lo parecen, lo cual es falso pues la soberanía es autócrata, característica de un tipología de Estado autoritaria, no 
democrática. Lo mismo ocurre en el segundo caso, cuando a pesar de que el origen del poder es democrático, la democracia formal propia del presidencialismo no puede ser correspondiente a un tipo de Estado del mismo sentido pues sus fines son oligárquicos, impedimento para el tipo de Estado democrático.

La democracia formal no corresponde al tipo de Estado democrático, en tanto los fines del poder político establecidos por esta forma de gobierno no se garantiza sean democráticos, es decir, beneficiarios en su totalidad del pueblo.

El régimen político tiene una referencia con los órganos constituidos del Estado, es decir, con todas aquellas instituciones que el hombre crea para dar forma al Estado y para hacer posible la consecución de los fines que los fundamentos del tipo de Estado le han otorgado. Por lo tanto, es necesario definir primero cronológicamente el tipo de Estado, y en función de esos principios diseñar la forma de gobierno.

Cuando el tipo de Estado es democrático, entonces las formas de gobierno que de él emanen deberán ser compatibles y coadyuvantes a la participación del pueblo en la toma de decisiones, de modo tal que se garantice que la soberanía pertenezca fácticamente al pueblo, y éste sea originario del poder político mediante el sufragio, y beneficiario del mismo mediante leyes y políticas públicas que garanticen su seguridad y desarrollo, fines para los cuales de constituye un Estado (Hobbes, 1980)

No hay que confundir los fines de "cualquier" tipo de Estado, con los fines de "un" tipo de Estado en específico; la filosofía política se ha encargado de despejar la primera incógnita al referir la finalidad de todo Estado como la seguridad y el desarrollo del individuo (Hobbes, 1980), mientras que la ciencia constitucional ha respondido a la cuestión de la finalidad de un tipo de Estado específico, el cual determina además de la garantía de seguridad y desarrollo, de quién emerge la capacidad de garantía, y quiénes gozan de ella.

La forma de gobierno es el camino, la manera y guía para que los fundamentos del tipo de Estado se concreticen en la realidad cotidiana de los individuos suscritos al pacto social que denominamos Estado. Para fines de explicación y comprensión, un ejemplo de esto es adecuado de la siguiente manera:

Si tenemos un tipo de Estado de corte democrático, luego entonces sus estructuras político-constitucionales, incluidas en el régimen de gobierno, deberán de ser proclives a la participación ciudadana e incluir los mecanismos adecuados para la consecución de este fin, instituciones de democracia semidirecta por ejemplo.

Por otra parte, si el tipo de Estado que nos ocupa es autocrático, entonces su régimen político deberá fundamentarse en la idea de recaer todo el peso, o por lo menos una gran parte de él, en una sola persona u órgano constituido a fin de que sea esa unidad la encargada de llevar a cabo toda decisión política dentro del 
Estado en cuestión; un ejemplo de ello es cuando en los regímenes monárquicos los reyes poseen la capacidad de iniciar leyes y decretos que en su mayoría no requieren de un verdadero consenso por parte de sus consejos; o bien su atribución de declarar guerras y comandar el ejército sin autorización de una contraparte o sin control alguno más aquél que le dicte la conciencia.

Este último punto merece un par de líneas para su disección, toda vez que Hobbes le ha dado un peso específico muy particular a esta condición del monarca de no responder a nadie más que a su propia voluntad:

"Frente a la índole absoluta del poder soberano como lo concibe Hobbes, ambos límites desaparecen. Por lo que hace a las leyes naturales y divinas, no es que Hobbes niegue la existencia de éstas, pero afirma (correctamente) que ellas no son como las leyes positivas; y no lo son porque no se pueden hacer valer con la fuerza de un poder común. Así pues, no son obligatorias exteriormente, sino sólo lo son interiormente, es decir, en conciencia" (Bobbio, 2001:95-96)

Cuando Bobbio hace referencia al absolutismo del poder soberano, en realidad lo que expresa no es la condición de summa potestas del monarca, sino de cualquier unidad que lo retiene de manera monopólica, aunque es válida la interpretación de absolutismo como el poder del rey dentro de la forma de gobierno monárquica que nos ocupa.

El límite que plantea Bobbio, es aquel que Bodino describe cuando puntualiza la diferencia entre el monarca y el tirano:

"La diferencia más clara entre un rey y un tirano es que el rey se apega a las leyes de naturaleza, mientras el tirano las transgrede" (Bodino, 1973:594)

Este límite desaparece según Hobbes, toda vez que la ley natural o divina no posee carácter tangible o aplicable, en función de que carece de un cuerpo judicial que constriña a los hombres a su estricto apego. Cualquier escolástico o especialista del derecho canónico podría replicar que la fe es un elemento mucho más fiable de constricción a la norma, pues legitima su existencia y además funciona de manera preventiva; o bien que la Iglesia, cualquiera que ésta sea, sujeta a sus fieles al apego a éstas como condicionante para su permanencia dentro del seno religioso.

Sin embargo, la ley natural o divina sólo es respetada cuando ésta se convierte en norma positiva, como consecuencia de que la segunda sí posee una redacción tangible, sujeta a jurisprudencia y revisión, y por supuesto sanción judicial en caso de violación. Las leyes naturales, si se les quiere interpretar como derechos universales del hombre, sólo adquieren ésta connotación cuando se plasman en un constitución o bien en una carta o tratado internacional reconocido por varios países; el caso es similar para las leyes divinas, éstas pueden estar sujetas a sanción judicial única y exclusivamente cuando el derecho canónico las ha 
reconocido y ha convertido en norma positiva las creencias teológicas pregonadas por la propia Iglesia, ejemplo para lo cual es bastante ilustrativo el fuero eclesiástico. Es prudente confirmar lo dicho por Hobbes, un monarca no está en momento alguno sujeto a leyes divinas en tanto éstas carecen de mecanismos de constricción fáctica, corpórea o tangible hacia el infractor, es decir el propio rey.

\section{El presidente: un tlatoani monarca}

Habíamos indicado en otros escritos siguiendo al Dr. Enrique Florescano que la imagen del ajaw o del tlatoani resume en sí misma la historia entera de Mesoamérica, y por ello es la figura central en las representaciones del cosmos, el territorio, el reino, el pasado o el poder. Desde la fundación de los primeros reinos el soberano se convierte en la figura más retratada en las capitales olmecas, zapotecas o mayas. Las funciones que el jefe de hombres tenía a su cargo: cabeza del reino, capitán de los ejércitos, sacerdote supremo, primer agricultor, puente de comunicación con los ancestros. El Tlatoani es el símbolo detentador único del máximo poder político que ha tenido vigencia en México, cuando menos desde 1917 (El Jefe Máximo de la Revolución Constitucionalista) caracterizando al presidencialismo mexicano durante todo el siglo $\mathrm{XX}$.

El símbolo del Tlatoani, significa la concentración del poder político y económico, bajo la venia de los dioses, en una sociedad náhuatl que manifestaba un nivel de desarrollo en el que se notaban la existencia de grupos sociales con diferentes intereses, pero que se relacionaban entre sí, de manera rutinaria, donde el Rey o Soberano, también conocido como Tlatoani ocupaba la cúspide del poder.

Según Roger Bartra afirma: "después de un estudio detenido de las fuentes históricas y de los resultados de las investigaciones arqueológicas, se define que la sociedad azteca había superado la etapa de la comunidad primitiva y erigido una sociedad clasista desarrollada". "A la llegada de los españoles a México, existía en la Gran Tenochtitlán una sociedad diferenciada en clases sociales que estaba organizada con una estructura jerárquica de poder político y diferenciada en sus funciones productivas, por lo que éste autor la define como un "modo de producción tributario", diferente al asiático y diferente al feudalismo, pues un desequilibrio interno en el desarrollo de las fuerzas productivas, ocasiona un desarrollo del aparato estatal como aglutinante político y económico de la sociedad". (Batra 1969: 213)

Los españoles sustituyeron en la estructura y relaciones de poder, a los soberanos tenochcas que usaban tecnologías intensivas en fuerza de trabajo, en donde el soberano era el que tenía la propiedad de la tierra y el derecho a explotar a la fuerza de trabajo, estos soberanos se conocían como tlatoanis (Bartra 1969: 217). La asociación inicial, del poder político y económico ejercido por el soberano autóctono, con el que a partir de agosto de 1521 empezaron a ejercer los españoles, se haya conocido, después de muchos años, como el poder del 
Tlatoani, en el que se mezcla lo autóctono con lo español, en rasgos que definen el ejercicio del poder en el México colonial y luego, en el independiente y moderno. Miguel León Portilla afirma que: "Los textos y pinturas de los indios por una parte, y las relaciones españolas por otra, constituirán las dos caras distintas del espejo histórico en el que refleja la conquista". (León Portilla 1976: X)

Tlatoani es el Señor, el Soberano, el Rey, el que tiene poder y lo ejerce sobre la gente, según la primera parte del Códice Mendocino como lo refiere Bartra, los tlanoanis mencionados por éste autor son: Tenochtli, Acamapichtli, Uitzilíhuitl, Chimalpopoca, Izcoatzin, Ueue Motecuçuma, Axayacatzin, Teçotzicatzin, Auitzotzin, y Motecuçumatzin que gobernaron entre 1325 y 1520. Los Tlatoanis recibían tributo de los calpullec: población de las comunidades y de los barrios y de los pochteca que eran mercaderes, asimismo el tlatoani era poseedor directo de tierras, lo cual es indicativo de que el poder político del soberano autóctono estaba fuertemente asociado al poder económico y al poder militar.

Esta conjugación de atributos y cualidades reconocidas en los nuevos Señores del Poder -los españoles recién llegados a América-, en donde se entremezclan las cualidades y condiciones del poder ejercido por los reyes y Príncipes autóctonos y las cualidades propias de los españoles reconocidas por los Reyes de España, es la connotación que en el curso de los años y los siglos va conformando el significado actual a la noción de Presidente Tlatoani.

El Presidente Tlatoani, es Rey, Príncipe, monarca dotado de poder y riquezas, propietario de las tierras, y poseedor de las vidas de los seres humanos que habitan dichas tierras. Pero además, tiene un amplio conocimiento del poder que posee y ejerce en todos los órdenes.

Un presidente, inserto en el marco jurídico de un régimen presidencialista posee un fuero político de alcances estratosféricos, incluso más fuerte que aquél que ostenta un legislador inserto en el propio régimen; regularmente, y tomamos como ejemplo la Constitución Política de los Estados Unidos Mexicanos, un presidente sólo puede ser acusado por delitos graves del orden común, o bien por traición a la patria, de acuerdo al artículo 108. La interpretación de este artículo es muy clara: el presidente es prácticamente inmune ante la violación de las leyes (tanto naturales como positivas) a menos que se trate de un asunto "grave" en donde la gravedad del acto o bien el episodio de traición a la patria, se determinará por actores políticos que o pertenecen a su partido (legisladores), o son designados y/o propuestos por el (ministros judiciales). Un presidente es tan inmune como lo es un monarca establecido en un régimen autoritario, salvo la distinción de que la inmunidad en la primera tiene una duración limitada correspondiente al encargo, mientras que en la segunda es vitalicia.

Esta condición de inmunidad se encuentra íntimamente relacionada con otro concepto que aporta Bodino con respecto a la soberanía, en un primer momento Bodino la define de la siguiente manera: 
"Se entiende por soberanía el poder absoluto y perpetuo de un Estado" "Quien es soberano de ninguna manera debe estar sujeto al mandato de otros, debe poder dar leyes a los súbditos, y cancelar o anular las palabras inútiles en ella para sustituirlas por otras, cosa que no puede hacer quien está sujeto a las leyes o personas que ejercen poder sobre él" (Bodino, 1973: 345,359)

Esta conceptualización la figura presidencial encaja a la perfección con la descripción que Bodino hace del soberano. Esta inferencia nos lleva a una afirmación atrevida pero con alto grado de veracidad: la soberanía en un régimen presidencialista es detentada por un solo individuo, con todas las implicaciones que esto conlleva.

La terminología "constitución" se utilizó de manera indiscriminada para definir tanto a la razón de ser y la teleología del poder político de un Estado, como a las estructuras políticas que permiten su funcionamiento, convergiendo ambas en la forma de gobierno; es conveniente puntualizar que la naturaleza de este error puede no ser de génesis teórica, sino más bien lingüística, caso en el cual Polibio quedaría eximido de tal responsabilidad intelectual y el yerro reposaría sobre Bobbio, o bien Fernández Santillán, traductor de la obra del griego al italiano el primero, y del italiano al español el segundo (Bobbio, 2001); hemos ya explicado la razón por la cual no deben de aglutinarse ambos conceptos en uno sólo, pero para objeto de mayor comprensión definimos "constitución" como sigue:

La constitución es el conjunto de decisiones políticas fundamentales (Schmitt, 1981), expresadas en el derecho positivo como normativa constitucional, cuyo establecimiento obedece a la suma de los factores reales del poder (Lasalle,1999: $11,19)$ que en determinado momento histórico poseían injerencia en los asuntos políticos del país, a esta suma se le debe de interpretar de manera dinámica y dialéctica (Covián,2000: 58), es decir, el acuerdo, negociación, conciliación y coyuntura de las decisiones políticas fundamentales para un Estado es un proceso en constante cambio y realimentación.

El presidencialismo es una forma de gobierno supuestamente correspondiente al tipo de Estado democrático, todo esto en función de que los órganos constituidos se integran mediante voto popular y la soberanía en esencia pertenece al pueblo. Además se caracteriza por una figura preponderante del Poder Ejecutivo, la existencia de dos poderes fácticamente subsumidos al primero, a saber el Poder Judicial y el Poder Legislativo; todo ello en el marco de la teoría de trias política de Montesquieu.

El presidente representa en este régimen un elemento sine qua non que además posee múltiples facultades y prerrogativas, tanto constitucionales como metajurídicas que le otorgan un poder superior al de sus "pares" legisladores y ministros. Estas características o potestades son la piedra angular sobre la cual se edifican nuestros argumentos para aseverar que el presidencialismo es una monarquía disfrazada. A continuación describimos algunas de ellas: 


\section{El sistema bicameral y la irresponsabilidad presidencial}

Históricamente, para ser precisos finales del Siglo XVIII e inicios del XIX, los regímenes parlamentarios se fortalecían frente a la figura monárquica, es decir, se vivió una lenta transformación de Estado autocrático a Estado democrático, fincado el gobierno parlamentario en la fuerza de una sola cámara de representantes sólida, unificada, y con poder real frente al monarca, lo que eventualmente ocasionó incomodidad en la figura real, por lo que tomando como fundamento la teoría de Jean Charles de Secondat, al momento de la creación del régimen presidencialista, se tomó la decisión de separar a las cámaras para dotar de mayor poder al presidente, lo que simbólicamente representó anular el poder del parlamento frente al monarca. (Covián, 2008: 139)

Evidentemente no significa que el individuo que asuma el cargo de presidente sea irresponsable en términos éticos o subjetivos, sino más bien a la carencia de potestades de la cámara o las cámaras de representantes para exigir responsabilidad política al titular ejecutivo.

En México existen precarios mecanismos de control que pudiesen confundirse con la potestad parlamentaria de exigir responsabilidad política al presidente de la república; en realidad el mecanismo contemplado por el artículo 110 de la Constitución Política de los Estados Unidos Mexicanos es el de responsabilidad de oficio, o jurídica, mediante la cual el presidente de la república sólo podrá ser acusado de delitos graves del fuero común, o bien por traición a la patria.

Para este apartado me permito citar a Covián (2008: 141)

"Si se observa con atención, en los regímenes democráticos los reyes no eran política, ni jurídicamente responsables ante los parlamentos, obviamente y en cuanto a lo único que no se les toleraba, era la traición a la corona. Por cierto, no deja de ser significativo que en nuestro país, en un caso extremo, si el presidente de la República fuera acusado penalmente traición a la Patria o delitos graves del orden común--, no conocería de la causa un tribunal, sino la cámara de senadores, a la que suele denominarse "cámara alta", como se llamaba a la cámara de los Lord en Gran Bretaña, la cual fue establecida por los reyes como contrapeso de la de representación popular -cámara de los "comunes"-y cuyos integrantes eran designados por los monarcas, teniendo como una de sus atribuciones la de juzgarlos en calidad de "pares nobiliarios" o "iguales aristócratas", diferentes a los representantes de los gobernados elegidos por éstos"

Dos elementos destacan de la cita de Covián: en las monarquías los reyes no eran responsables ni jurídica ni políticamente ante el parlamento, sólo podían ser acusados por traición a la corona, tal y como hoy en día los presidentes gozan de un fuero extraordinario que les permite actuar sin control político alguno, bastando no incurrir en traición a la patria o algún delito grave; en el caso extremo en el cual un presidente fuera acusado, su caso no lo conocería un tribunal ordinario, sino la 
cámara de senadores, tal y como se hacía en las monarquías inglesas en donde el rey era juzgado por sus pares aristócratas conformados en la cámara de los Lords.

\section{Capacidad de iniciativa de ley y derecho de veto presidencial}

No se cuestiona en momento alguno la operatividad e incluso necesidad de que el presidente pueda tener facultades de iniciativa legislativa, toda vez que al ser él el jefe de gobierno, debe conocer las necesidades de su administración, las trabas legales que enfrenta y los aspectos urgentes a legislar. Sin embargo, cuando se da el maridaje entre esta prerrogativa y el derecho de veto, las cosas se complican.

El hecho de que la figura presidencial pueda vetar o impedir la publicación y entrada en vigor de una ley aprobada por el Congreso implica una invasión descarada de la competencia legislativa de un órgano parlamentario, concebida únicamente para fortalecer la figura del presidente monarca (Covián, 2008: 142); supongamos que está en juego la aprobación de nuevas atribuciones para un órgano constituido, o bien una institución del Estado en cuestión, y que esas atribuciones pueden ser ejercidas para los intereses de varios grupos de poder o bien en beneficio del pueblo. Si el presidente en turno debe su posición al apoyo de ciertas oligarquías, es de esperarse que en caso de poseer tales atribuciones haga uso de ellas en pro de la causa de estos grupos de poder; en cambio si lo mismo pretendiese hacer la fracción parlamentaria del presidente dentro de una asamblea de representantes, la primera debería de enfrentarse contra los intereses de los demás miembros de la segunda, los cuales en el mejor de los casos corresponden a las de grupos menos poderosos y más vulnerables o menos favorecidos. Supongamos que en el congreso la fracción que representa los intereses oligarcas no logra imponer su voluntad en el acuerdo y las atribuciones en juego son concedidas a un órgano constituido distinto a la presidencia, como el congreso por ejemplo. En un régimen parlamentario, democrático por excelencia, la discusión llegaría a su fin y el parlamento ejercería sus funciones de acuerdo a la voluntad de las fuerzas políticas con mayor representación en el órgano colegiado; en un régimen presidencial, o de monarquía oculta, el presidente podría "vetar" dicha ley, con lo cual obligaría a la asamblea de representantes a corregir o volver a aprobar dichas atribuciones, pero esta vez con una mayoría superior a la originalmente obtenida. En el régimen presidencialista mexicano, el presidente veta la ley que concedía tales atribuciones al congreso, debiendo éste último aprobar la misma iniciativa esta vez por las dos terceras partes de los integrantes de cada una de las cámaras, de lo contrario la ley nunca conocerá entrada en vigor. Ahora bien, si a nuestro hipotético pero altamente factible caso agregamos el hecho de que el presidente también puede iniciar leyes, y que existen grupos de poder interesados en que sea la figura presidencial la que ostente las atribuciones en disputa, resulta bastante probable que una iniciativa que emane del titular del poder ejecutivo encuentre resonancia de mayoría en el congreso, sin posibilidad lógica de veto presidencial por supuesto. 
En conclusión, podríamos decir que cuando una ley no es del agrado del presidente-monarca se requieren dos terceras partes de la aprobación de ambas cámaras, mientras que cuando una ley favorece al ejecutivo, basta el voto aprobatorio de la mitad más uno de los integrantes de las cámaras, y en algunos casos sólo en una de ellas.

Esta contundente afirmación nos permite vislumbrar nuestra quinta motivación: facilidad presidencial para aprobar o vetar leyes según su conveniencia o voluntad.

\section{El ejercicio permanente del poder ejecutivo frente al intermitente del poder legislativo}

La idea de por qué este es uno de los factores por los cuales un presidente es superior en todo aspecto a cualquier otro órgano constituido del Estado, es bastante lógica, es decir detenta el poder por más tiempo que sus pares en términos reales. Me permito citar a Covián de nueva cuenta para fines explicativos:

"Esta situación favorece al presidente-monarca cuyos ancestros diseñaban diversas estrategias para evitar que los parlamentos se reunieran para sesionar, porque sin sesiones no había resoluciones y por ende, tampoco limitaciones para los reyes, quienes trataban de mantener dispersos a los representantes populares, o bien, en caso de no lograrlo, procuraban que las reuniones plenarias sólo se realizaran durante períodos preestablecidos, fuera de los cuales no era posible deliberar sobre algún asunto o tomar alguna decisión, sencillamente porque los parlamentos estaban en receso. Dicho en otros términos, a menor parlamento, mayor monarca y a menor posibilidad de decidir de los "comunes" o sus equivalentes, mayor capacidad real de los reyes para ejercer el poder, sin estar sometidos a los límites señalados por las asambleas mediante sus resoluciones" (Covián, 2008: 144-145)

Queda bastante clara la intención que se tuvo al diseñar los llamados "periodos ordinarios de sesiones" al momento de establecer el tiempo de duración del ejercicio legislativo por parte de las cámaras de representantes, en uno más de los intentos de debilitar al parlamento, cuya creciente influencia amenazaba los privilegios de la monarquía y sus beneficiados.

La actividad del presidente es estable en tanto no requiere de consenso más que con sus propios secretarios de Estado, mismos que son nombrados y removidos por el presidente sin ninguna posibilidad real de negociación, y la actividad legislativa es inestable por naturaleza en tanto conlleva el choque y debate de posturas plurales, renovación de las Cámaras por elecciones, todas con argumentos válidos y de relativa representatividad ciudadana, tenemos como resultado que el ejercicio presidencial es mucho más estable que el ejercicio 
parlamentario, lo cual no implica en ningún momento que uno sea mejor o más democrático que otro.

Este argumento constituye un hecho: ejercicio constante y estable del poder ejecutivo, frente al ejercicio intermitente e inestable del poder legislativo.

\section{Incapacidad del órgano u órganos legislativos para ejercer a plenitud sus funciones en períodos extraordinarios}

La lógica de este argumento es, mutatis mutandis, la misma que el anterior debido a que su génesis obedece a la voluntad del monarca por debilitar al parlamento.

En nuestro país existe la posibilidad de que cuando el Congreso no se encuentre dentro de un "periodo ordinario de sesiones" se pueda convocar a uno extraordinario, sin embargo sólo para atender los asuntos para los cuales dicho evento fue convocado, cerrando la posibilidad de ejercer muchas otras atribuciones que la ley le confiere a esta asamblea de representantes y que exceden las limitantes tópicas que para efectos de la convocatoria extraordinaria se expidieron.

“¿cuál es la razón de que no pueda ejercer cualquiera de sus atribuciones (la cámara de representantes) simplemente porque esté deliberando en determinado día o mes calendario? Cualquier respuesta a este pregunta en términos de un Estado democrático tendría que ser en el sentido de no justificar esta limitación" (Covián, 2008: 145)

Aparece el interés del presidente-monarca porque las cámaras de representantes sesionen lo menos posible y de la forma más limitada permisible, toda vez que ésta es por naturaleza teórica, el órgano de control por antonomasia del poder ejecutivo.

\section{El formato del informe presidencial ante el órgano parlamentario}

En los regímenes presidencialistas se acostumbra que por mandato constitucional se lleva a cabo anualmente una ceremonia solemne y protocolaria en la cual el titular del poder ejecutivo acude a la sede del congreso para presentar su informe anual de actividades y así rendirle cuentas a la población mediante sus representantes; cabe señalar que en este acto de grandilocuente naturaleza no es posible interpelar al presidente de la república, toda vez que un acto de semejante descortesía violentaría la esfera competencial del presidente.

El párrafo anterior bien pudo corresponder a un autor afín a la teoría neoliberal de la democracia, compatible con la forma de gobierno presidencialista y el tipo de Estado liberal burgués de derecho; obviamente no concuerdo en ningún momento con tales planteamientos. 
Resulta ingenuo creer que cuando el presidente da lectura a su informe, o bien lo envía al congreso como ha ocurrido en los dos más recientes informes presidenciales en México, el presidente de la República se encuentre ejerciendo un acto de rendición de cuentas y que está haciendo de su administración un gobierno de transparencia y responsabilidad para con los ciudadanos; si a esta aseveración le sumamos la irresponsabilidad política del presidente frente a los representantes popular, tal y como ya lo hemos visto, el congreso se ve imposibilitado para sancionar al presidente, o bien darle continuidad a su ejercicio, independientemente de los resultados ofrecidos por éste, el mal manejo de los fondos, la opacidad gubernamental, la omisión legislativa en tópicos de relevancia como consecuencia del veto presidencial, la mala conducción de la política económica; no importa cuál sea el contenido del informe presidencial, de cualquier modo no se le podrá sancionar en lo más mínimo al titular del ejecutivo.

Es evidente la naturaleza caprichosa del "protocolo solemne" en el cual no se le puede interpelar al presidente de la república durante la lectura de su informe, ni si quiera una vez finalizado el mismo; este acto, lejos de significar un respeto a la esfera competencial de cada uno de los poderes, es un acto de vejación hacia las facultades de representación popular de un congreso, ¿o acaso todos los ciudadanos se encuentran complacidos por las acciones y omisiones de su presidente?, es poco probable.

Covián lo disecciona de la siguiente manera:

"En términos de un ejercicio democrático del poder político, no tiene ninguna justificación que el presidente de la República no pueda ser interrumpido por los representantes populares sea en una sesión como en la que presenta su informe 0 en cualquiera otra ocasión en la que tenga que discutirse el contenido o el sentido de sus decisiones. Las palabras "protocolaria" y "solemne" que frecuentemente se emplean para calificar a la ceremonia de presentación del informe presidencial no tienen nada que ver con el diseño estructural, ni con la aplicación de las estructuras de un régimen político de un Estado democrático, en el que el poder debe ejecutarse conforme a sistemas de control de diverso tipo, uno de los cuales se refiere a las relaciones entre los órganos constituidos" (Covián, 2004:205, 206) Estos sistemas de control a los cuales alude Covián, son aquéllos que son propios a un régimen parlamentario, en donde el titular del ejecutivo sí es políticamente responsable por sus acciones y omisiones, y el parlamento puede interpelar, debatir, e incluso remover o dar continuidad a un mandatario dependiendo de la calidad y orientación del ejercicio del poder que detenta.

Covián profundiza esto en otra de sus obras:

"Actualmente, el presidente "tlatoani, monarca" asiste al congreso o a la asamblea por disposición constitucional, pero en todo caso, sin que de lo que diga u oculte dependa su condición de gobernante. Su origen electivo no es pauta para que se siga considerando implícitamente que no es "igual" que los demás representantes 
populares y que por ende, debatir con ellos sería denigrante o por lo menos, improcedente. La mejor demostración de lo anterior es el hecho de que no obstante el mismo origen representativo del jefe de gobierno y de los miembros del congreso o de la asamblea, la idea de una jerarquía superior del primero sobre los segundos prevalece, siendo equivalente al origen aristócrata de los reyes, frente a la condición de "comunes" de los representantes del pueblo, situación que obviamente no se hace explícita en los regímenes presidenciales, pero que no se puede disfrazar lo suficiente como para que un científico social sea incapaz de descubrirla” (Covián, 2008: 148, 149)

Aparece contundentemente la imposibilidad de los representantes populares de interpelar al presidente de la república durante su informe, cuyo contenido es irrelevante en tanto no se puede discutir con su emisor en lo más mínimo; lo cual nos recuerda la imposibilidad de los "comunes" o súbditos para discutir con el rey pues no pueden ser considerados en momento alguno como pares.

\section{Facultad presidencial de nombrar a su gabinete}

Cuando la monarquía dominaba gran parte de los territorios de occidente, existían algunas figuras conocidas como títulos nobiliarios, los cuales representaban la carta de aceptación de un hombre a la aristocracia monárquica. Baronías, marquesados, condados, vizcondados y ducados eran títulos que correspondían al honor de ser nombrado una persona poderosa en tanto se era cercano o relativo al rey, éste último era el único capaz de otorgar y despojar a tales hombres de sus títulos. Hoy día se conservan este tipo de prebendas en las monarquías constitucionales, y en algunas despóticas en mucho menor grado.

Existe analogía entre la dotación de títulos nobiliarios por parte del monarca y la designación unilateral y voluntaria de los secretarios de Estado del presidente de la República; en ambos casos basta con contar con la gracia del presidente o monarca para ser condecorado con un título o nombramiento que vendrá acompañado por supuesto de rentas económicas de considerable prestación, así como del estatus social requerido para rodearse del glamur y los lujos de la aristocracia.

"En efecto" - dice Covián-"estos funcionarios juegan el papel de los aristócratas cortesanos del rey, cuya posición política y cuyos privilegios dependen totalmente de la voluntad del "presidente-monarca", el cual literalmente, de la noche a la mañana puede convertir en "conde" o "duque" - secretario de Estado o director de una entidad paraestatal - a un ilustre desconocido, de ser el caso, sin experiencia alguna en el área respectiva y sin una preparación profesional medianamente aceptable..." (Covián, 2008: 149)

Aparece la analogía entre la designación discrecional de los secretarios de Estado por parte del presidente, y el otorgamiento de prebendas nobiliarias por parte del 
monarca. Aparecen también importantes beneficiarios de negocios, concesiones, trato preferencial de impuestos con hacienda para los empresarios favoritos del presidente en turno.

\section{Potestad presidencial para designar a los ministros de las cortes superiores}

Cuando se crea el sistema presidencialista, tomando como basamento teórico la separación de poderes de Esconda, se le da preferencia a la forma de elección popular para las tres esferas competenciales del Estado, por lo que el origen del poder Judicial era también popular.

Con el paso del tiempo, y a medida que el individualismo propio del liberalismo entra en auge, comienza a ser problemático este hecho pues en una gran cantidad de casos los individuos o particulares se enfrentaban jurídicamente con los órganos constituidos del Estado mediante las figuras de amparo (ej. México, España), o de queja (Alemania). Este recurso explotado en manos de la burguesía a menudo chocaba con los intereses del presidente de la República, o bien lo confrontaban de manera directa, fallando en muchos casos a favor del agraviado, dejando mal parada la figura presidencial.

Este "defecto" estructural del diseño del régimen presidencial-monárquico se corrigió bajo el argumento de que no se podía dejar al libre juego político-electoral la enorme capacidad y responsabilidad que requiere el ejercicio judicial, además de que no se podía exponer este importantísimo cargo al sesgo ideológico y debía de tener carácter inamovible e imparcial, por lo que una terna propuesta por el ejecutivo aprobada por el legislativo sería lo más prudente.

La solución a este "defecto" parece plausible a primera vista, pero una vez expuesta a un análisis riguroso de sus procesos, encontramos una vez más la naturaleza monárquica de este tipo de resoluciones.

Desde el momento en el cual el presidente escoge a tres individuos para proponerlos ante el legislativo queda abierta la puerta de la lealtad, el compromiso y compadrazgo para con aquél que le ha sugerido para ser ministro de la corte suprema de justicia; esta condición se agrava cuando se anexa al proceso la condición de que cuando el senado no aprobase dos ternas consecutivas por dos terceras partes de sus integrantes, el ejecutivo designará de manera arbitraria y unilateral a los individuos que integrarán esta corte superior; por si esto fuera poco, si la propia cámara de senadores no logra deliberar su decisión en un plazo máximo de treinta días, el presidente en automático aprobará su propia terna.

Por todas estas razones, un ministro de la Suprema Corte de Justicia de la Nación debe su cargo al presidente de la república, lo cual lógicamente sesgará sus resoluciones a favor de su tendencia. Tesis demostrada en la investigación sobre el presidencialismo en México del Dr. Jorge Carpizo. Aparece el control 
presidencial sobre el sistema judicial mediante la lealtad y el compromiso de los ministros de la corte suprema para con la figura que los propuso para ministros.

\section{La doble autoridad del presidente: como titular del ejecutivo y como líder informal del partido que representa}

Los partidos políticos, sobre todo aquellos que Katz y Mair (1995) bautizaron como partidos "cártel", orientan todos sus esfuerzos electorales para conseguir cargos, para tener acceso al poder, toda vez que éstos fundamentan sus acciones en función de los recursos que pueden administrar, gestionar o conceder, así como el tipo de prebendas que puedan otorgar en una negociación. Para todos estos fines, en todo régimen presidencial el cargo público de la presidencia de la república es el puesto más codiciado al cual puede aspirar cualquier partido político, es por eso que el presidente de la república se ve en una posición de liderazgo en su partido, y es él mismo quien decide gran parte de la actividad del propio partido e incluso las personas que ocupan dirigencias y candidaturas dentro del mismo.

“... el "presidente tlatoani monarca" es en realidad el jefe del partido político al que pertenece y consecuentemente, es él quien distribuye el poder entre sus militantes y simpatizantes y es a él a quien éstos rinden cuentas de su ejercicio. Este rey sin corona visible, castiga también a quienes no le obedecen o no cumplen con la función que se les encomienda, sin que exista otra posibilidad de salvación política para ellos, distinta a la clemencia o al indulto del propio monarca" (Covián, 2008:155)

Si a esta condición de liderazgo en el partido sumamos la posibilidad que conlleva la misma para nombrar al candidato para sucederlo en el "trono", tenemos otra motivación: la doble autoridad del presidente (como titular del ejecutivo, y como líder del partido al cual representa), le permite designar a su sucesor, tal y como lo hacían los reyes en las monarquías.

En este artículo no pretendemos emitir algún juicio de valor o adjetivar al presidencialismo, o a la monarquía; el propósito es única y exclusivamente demostrar que el régimen presidencialista no corresponde a un ejercicio del poder de corte democrático, sino más bien autocrático. Podría decirse, en términos de Bodino, que el presidencialismo es una forma de gobierno "democrática monárquica" (Bobbio, 2001:87), en tanto la soberanía original reside en el pueblo por mandato constitucional (no se pretende ignorar el origen electoral del poder), pero se ejerce de manera unipersonal, pese a lo que se sostenga en la teoría de la división de poderes, ya que el propio Bodino ha señalado ésta como una falacia en tanto una esfera siempre prevalecerá sobre las otras (Bobbio, 2001: 85). Después de todo ahora comprendemos mejor porqué en la Constitución Política de los Estados Unidos Mexicanos la palabra "Supremo" precede a "Poder Ejecutivo". 


\section{Conclusiones}

En la conjugación de atributos y cualidades reconocidas en los nuevos Señores del Poder -los españoles recién llegados a América-, en donde se entremezclan las cualidades y condiciones del poder ejercido por los reyes y Príncipes autóctonos y las cualidades propias de los españoles reconocidas por los Reyes de España, es la connotación que en el curso de los años y los siglos va conformando el significado actual a la noción de Presidente Tlatoani monarca.

La actividad legislativa inestable por naturaleza conlleva el choque y debate de posturas plurales, todas con argumentos válidos y de relativa representatividad ciudadana, tenemos como resultado que el ejercicio presidencial es mucho más estable que el ejercicio parlamentario, lo cual no implica en ningún momento que uno sea mejor o más democrático que otro.

Se produce la analogía entre la designación discrecional de los secretarios de Estado por parte del presidente, y el otorgamiento de prebendas nobiliarias por parte del monarca.

El control presidencial sobre el sistema judicial mediante la lealtad y el compromiso de los ministros de la corte suprema para con la figura que los propuso para ministros. Por lo menos a manera de propuesta prácticamente son designados.

El régimen presidencialista no corresponde a un ejercicio del poder de corte democrático, sino más bien autocrático. Podría decirse, en términos de Bodino, que el presidencialismo es una forma de gobierno "democrática monárquica". Donde tanto el presidencialismo como la monarquía limitan el ejercicio, espacios y derechos eminentemente democráticos de las sociedades contemporáneas.

La doble autoridad del presidente (como titular del ejecutivo, y como líder del partido al cual representa), le permite designar a su sucesor, tal y como lo hacían los reyes en las monarquías.

\section{Bibliografía}

- $\quad$ BARTRA, Roger (1969), "El Modo de Producción Asiático: Problemas de la historia de los países coloniales". Ed. Era. México.

- $\quad$ BOBBIO, Norberto (2001), La teoría de las formas de gobierno en la historia del pensamiento político, México, Fondo de Cultura Económica, Traducción de José Fernández Santillán.

- $\quad$ BODINO, Jean (1973), Los seis libros de la república, Madrid, Aguilar.

- COHEN, Abner. (1985), "Antropología Política: El análisis del simbolismo en las relaciones de poder". en Llobera, J.R. "Antropología Política” Ed. Anagrama. Barcelona. 
- COVIÁN, Andrade Miguel (2008), ¿Cómo transformar el sistema político sin reformar el Estado social?, México, Centros de Estudios de Ingeniería Política y Constitucional A. C.

- COVIÁN, Andrade Miguel (2000), La teoría del rombo, México, Centros de Estudios de Ingeniería Política y Constitucional A. C.

- COVIÁN, Andrade Miguel (2004), El sistema político mexicano. Legitimidad electoral y control del poder político, México, Centros de Estudios de Ingeniería Política y Constitucional A. C.

- HOBBES, Thomas (1980), Leviatán O la materia, forma y poder de una república eclesiástica y civil, México, Fondo de Cultura Económica, Segunda edición en español.

- $\quad$ KATZ, Richard y MAIR (1995), Peter Changing model of party organization and party democracy: The emergence of the cartel Party, en Party Politics. Vol. I, No. 1.

- LASSALLE, Ferdinand (1999), ¿Qué es una Constitución?, México, Colofón.

- LEÓN Portilla, Miguel (1976), "La Visión de los Vencidos". Ed. UNAM. México. Séptima Edición.

- $\quad$ SCHMITT, Carl (1981), Teoría de la Constitución, México, Editora Nacional.

- SILVA Herzog, Jesús (1974). "El Agrarismo Mexicano y la Reforma Agraria". Ed. FCE. México. 